\title{
SYNTHESIS, CHARACTERIZATION AND ANTI-FUNGAL POTENTIAL EVALUATION OF 1,4 THIAZINE DERIVATIVES BY MANNICH BASES
}

\author{
SINDHU.T.J ${ }^{1 *}$ MEENA CHANDRAN² , K. KRISHNAKUMAR².
}

1. Department of Pharmaceutical Chemistry, Sanjo College of Pharmaceutical Studies Vellappara, Palakkad, Kerala, India 2. Department of Pharmaceutical Chemistry, St.James College of Pharmaceutical Sciences, Chalakkudy, Kerala, India

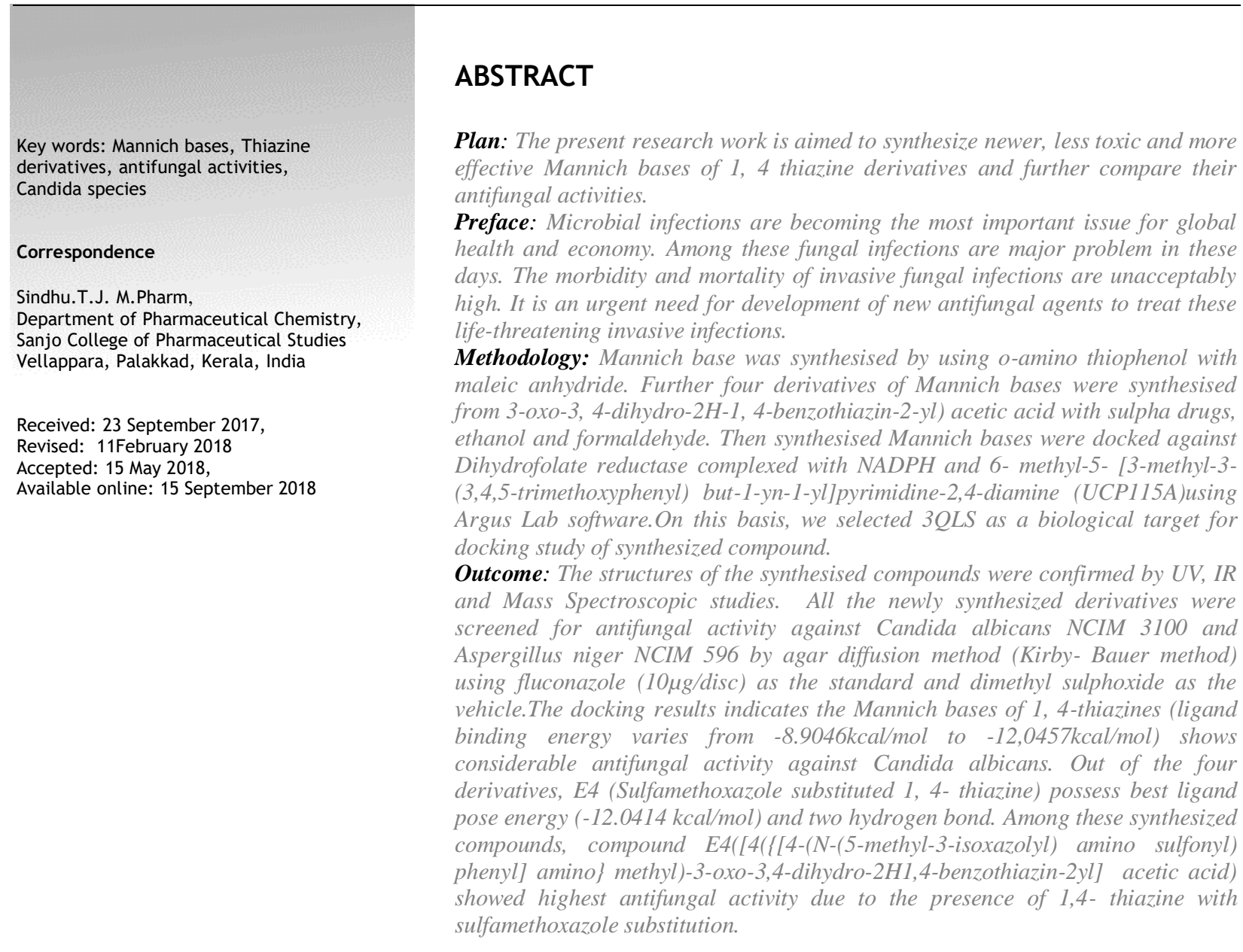

\section{INTRODUCTION}

Heterocycles are important and unique class of compounds; they make up more than half of all known organic compounds and have a wide range of physical, chemical and biological properties having a broad spectrum of reactivity and stability. ${ }^{1}$

Corresponding author email: sindhutj81@gmail.com

Hygeia.J.D.Med. Vol.10 (1), August 2018

(C) All rights reserved Hygeia journal for drugs and medicines, 22293590

Rid: M-5593-2018 
Heterocycles are widely distributed in nature and play a vital role in metabolism because their structural subunits exist in many natural products, including vitamins, hormones, antibiotics, and alkaloids as well as pharmaceuticals, agrochemicals, dyes, and many others. ${ }^{2}$ In addition to naturally occurring compounds, a large number of synthetic heterocyclic compounds with important physiological and pharmacological properties are also known. ${ }^{3}$ These compounds provide scaffolds on which pharmacophores can arrange to yield potent and selective drugs. ${ }^{4}$ Moreover, compounds having heterocyclic moieties display enhanced solubility and salt-formation properties that enable their oral absorption and bioavalability ${ }^{5}$. Among heterocyclic compounds, nitrogen-containing heterocycles like Mannich bases are the core structures of numerous biologically active compounds and exhibit numerous applications in chemistry, biology and other sciences ${ }^{6}$. They are the building blocks of life due to their wide occurrence in nature and central roles in the chemical reactions that occur in all organisms ${ }^{7}$ Furthermore, nitrogen-containing heterocycles play an important role in co-ordination chemistry ${ }^{8}$.

In these days, development of drug resistance is a major problem and to overcome this situation, it is necessary to synthesize new classes of compounds. Mannich bases containing bridged $\mathrm{N}$-atom exhibit pronounced biological activities. ${ }^{9}$ Mannich bases, beta-amino ketones carrying compounds, are the end products of Mannich reaction ${ }^{10,11}$. Mannich reaction is a nucleophilic addition reaction which involves the condensation of a compound with active hydrogen(s) with an amine (primary or secondary) and formaldehyde (any aldehyde) ${ }^{12}$. General Mannich reaction is given below.

$$
\mathrm{R}_{2} \mathrm{NH}+\mathrm{HCHO}+\mathrm{R}_{2} \mathrm{CHCOR} \underset{-\mathrm{H}_{2} \mathrm{O}}{\longrightarrow} \mathrm{R}_{2} \mathrm{~N}-\mathrm{CH}_{2}-\mathrm{R}_{2} \mathrm{C}-\mathrm{COR}
$$

Mannich bases also act as important pharmacophores or bioactive leads which are further used for synthesis of various potential agents of high medicinal value which possess aminoalkyl chain. The examples of clinically useful Mannich bases which consist of aminoalkyl chain are cocaine, fluoxetine, atropine, ethacrynic acid, trihexyphenidyl, procyclidine, ranitidine, biperidene, ${ }^{13-15}$ and so forth. Mannich bases are known to play a vital role in the development of synthetic pharmaceutical chemistry. The literature studies revealed that Mannich bases are very reactive and can be easily converted to other compounds, for example, reduced to form physiologically active amino alcohols. ${ }^{16}$

Mannich bases are known to possess potent activities antiinflammatory, ${ }^{17,18}$ anticancer, ${ }^{19,20}$ antifilarial $^{21}$, antibacterial ${ }^{22,23}$, antifungal ${ }^{23,24}$ anticonvulsant, ${ }^{25}$ anthelmintic, ${ }^{26}$ antitubercular ${ }^{27,28}$, analgesic ${ }^{29}$, anti-HIV, antimalarial, ${ }^{30}$ antipsychotic. ${ }^{31}$ antiviral $^{32}$ activities and so forth. Along with biological activities Mannich bases are also known for their uses in detergent additives, resins, polymers, surface active agents, and so forth. Prodrugs of Mannich bases of various active compounds have been prepared to overcome the limitations. ${ }^{33}$ Mannich bases (optically pure chiral) of 2-naphthol are employed for catalysis (ligand accelerated and metal mediated) of the enantio selective carbon-carbon bond formation. Mannich bases and their derivatives are intermediates for the synthesis of bioactive molecules ${ }^{34,} 35$. Mannich reaction is widely used for the construction of nitrogen containing compounds. ${ }^{36}$ Mannich bases have gained importance due to their application in antibacterial and fungal activity ${ }^{37}$ and other applications are in agrochemicals such as plant growth regulators. Candida species are important human pathogen that is best known for causing opportunist infections in immune compromised hosts ${ }^{38}$.The study suggests that1, 4-thiazine derivatives shows potent antifungal activity. It is sad to note that one third of the world population is infected with fungi and the incidence of the disease is increased every year and it is a problem in many parts of the world. 
Although many active antifungal agents have since been developed, a disturbing co-occurrence with the use of present drug as single agent has developed drug resistance and possesses numerous adverse reactions. Therefore it is a clear need for the discovery of new derivatives with antifungal activity for the management of fungal infections. This has made use to investigate for new thiazine derivatives for finding more effective antifungal agents.

In continuation of synthetic work on biologically active compounds, it is interesting to note that the Cephalosporin contain a 1, 3-thiazine ring, which is active core of Cephalosporin $\beta$-lactam antibiotics. It has been observed that there is no Cephalosporin with a 1, 4- thiazine nucleus. In the light of above fact we have synthesized some new 1,4-thiazine derivatives by changing sulphur to the fourth position from the third position by Mannich reaction, and compare the activity of these synthesized 1,4 thiazine derivatives.

Then synthesised Mannich bases were docked against Dihydrofolate reductase complexed with NADPH and 6- methyl-5- [3-methyl-3-(3, 4, 5-trimethoxyphenyl) but-1-yn-1-yl] pyrimidine-2, 4-diamine (UCP115A) using Argus Lab software. Candida albicans cause fungal blood stream infections that are associated with significant mortality. As part of an effort to develop potent and selective antifolates that target dihydrofolate reductase (DHFR) from Candida species. Three ternary crystal structures of Candida albicans DHFR (CaDHFR) bound to novel propargyl-linked analogs. Consistent with earlier modeling results, these structures show that hydrophobic pockets in the binding site may be exploited to increase ligand potency. Crystal Structures of Candida albicans Dihydrofolate Reductase Bound to PropargylLinked Antifolates Reveal the Flexibility of Active Site Loop Residues Critical for Ligand Potency and Selectivity. On this basis, we selected 3 QLS as a biological target for docking study of synthesized compounds ${ }^{39}$.

The aim of our present study is the synthesis of Mannich derivatives and study of their activities. We hope that this work will be of definite interest for researchers concerned with Mannich reaction.

\section{MATERIALS AND METHODS}

O-aminothiophenol, maleic anhydride, formaldehyde, diethyl ether were procured from MERCK. Other solvents and chemical reagents were collected from CHEMCO and NICE pharmaceuticals. Instruments used are SHIMADZU IR Affinity- 1 spectrometer, UV 1700 spectrometer and FTMS $\{1,2\}+p$ ESI full lock ms (100.00-2000.00).

\subsection{Melting point determination:}

The melting points of the organic compounds were determined by open capillary tube method and are uncorrected.

\subsection{Solubility of compounds}

The solubility of the synthesized compounds was tested in various solvents like water, ethanol, methanol, chloroform, benzene etc. 


\subsection{Thin layer chromatography}

TLC represents the most useful and precise technique to identify the formation of new compounds and also to determine the purity of the compound. $R_{\mathrm{f}}$ value is an important parameter and is characteristic for each compound in the same solvent system. So $\mathrm{R}_{\mathrm{f}}$ values of the synthesized compounds were determined. The solvent system used is Acetone, methanol, chloroform (2:1:1).

\subsection{Synthesis of (3-oxo-3, 4-dihydro-2H-1, 4-benzothiazin-2-yl) acetic acid $\left(S T_{1}\right)$}

To a solution of maleic anhydride $(0.05 \mathrm{~mol})$ in diethyl ether $(20 \mathrm{ml})$ a solution of o- amino thiophenol $(0.05 \mathrm{~mol})$ or in diethyl ether $(20 \mathrm{ml})$ was added. The reaction mixture was stirred at room temperature for 2 hours. The precipitate was filtered and washed with ether and recrystallized from $70 \%$ ethanol to get pure $\left(\mathrm{ST}_{1}\right)$. Yield: $95 \%$. Melting point: $201^{\circ}$. Purity was assessed by TLC as a single spot (The solvent system used is Acetone, methanol, chloroform $(2: 1: 1)^{40}$.

\subsection{Synthesis of Mannich bases of 1, 4 thiazine derivatives}

A mixture of compound $\left(\mathrm{ST}_{1)}(0.01 \mathrm{~mol})\right.$ was dissolved in ethanol $(15 \mathrm{ml})$ followed by addition of sulfa drugs $(0.01 \mathrm{~mol})$ and formaldehyde $(0.02 \mathrm{~mol})$ to undergo Mannich reaction. The reactants were refluxed for 2-10 hours with continuous stirring at $70-75^{\circ} \mathrm{C}$. The completion of reaction was checked by TLC. After completion of reaction the mixture was poured into ice water and kept in a refrigerator overnight. The product precipitated out and was filtered, dried and recrystallised with $80 \%$ ethanol to give solid compounds. Purity was assessed by TLC as a single spot (The solvent system used is Acetone, methanol, chloroform (2:1:1).

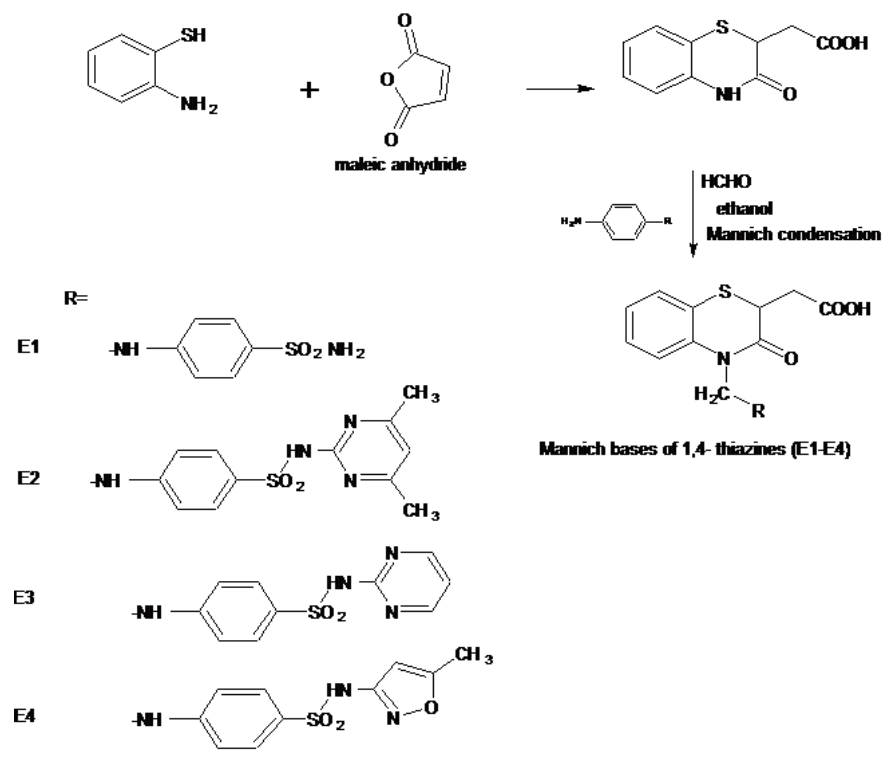

Synthesis of Mannich bases of 1, 4 thiazine derivatives 
Table No 1: Physical data of newly synthesized Mannich bases of 1, 4- thiazines.

\begin{tabular}{|c|c|c|c|c|c|c|}
\hline Compound & $R$ & Molecular Formula & Mol. wt & $M . P\left({ }^{\circ} \mathrm{C}\right)$ & $\%$ yield & $R_{f}$ value $^{*}$ \\
\hline E1 & & $\mathrm{C}_{17} \mathrm{H}_{17} \mathrm{O}_{5} \mathrm{~S}_{2} \mathrm{~N}_{3}$ & 407.20 & $233-235$ & 75 & 0.73 \\
\hline E2 & & $\mathrm{C}_{23} \mathrm{H}_{23} \mathrm{O}_{5} \mathrm{~S}_{2} \mathrm{~N}_{5}$ & 513.33 & $188-190$ & 70 & 0.69 \\
\hline E3 & & $\mathrm{C}_{21} \mathrm{H}_{19} \mathrm{O}_{5} \mathrm{~S}_{2} \mathrm{~N}_{5}$ & 485.0 & $215-217$ & 68 & 0.70 \\
\hline E4 & & $\mathrm{C}_{21} \mathrm{H}_{20} \mathrm{~N}_{4} \mathrm{O}_{6} \mathrm{~S}_{2}$ & 488.27 & $186-188$ & 74 & 0.74 \\
\hline
\end{tabular}

*solvent system: Acetone: Methanol: Chloroform (2:1:1)

Table No. 2: Coded IUPAC names of the synthesized compounds

\begin{tabular}{|c|c|c|}
\hline Code No & Structure & IUPAC Name \\
\hline E1 & & $\begin{array}{c}{[4(\{[4 \text { (aminosulfonyl) phenyl }] \text { amino }\} \text { methyl })-3 \text { - }} \\
\text { oxo-3,4-dihydro-2H-1,4benzothiazin-2-yl }] \text { acetic } \\
\text { acid. }\end{array}$ \\
\hline E2 & & $\begin{array}{l}\text { [4(\{[4-(4,6-dimethyl2-pyrimidiny) amino } \\
\text { sulfonyl) phenyl] amino }\} \text { methyl)-3-oxo-3,4- } \\
\text { dihydro-2H-1,4benzothiazin-2-yl] acetic acid }\end{array}$ \\
\hline E3 & & $\begin{array}{c}\text { ([4(\{[4-N2-pyrimidinyl amino sulfonyl) phenyl }] \\
\text { amino }\} \text { methyl) -3-oxo-3,4-dihydro- } \\
\text { 2H1,4benzothiazin-2-yl]acetic acid }\end{array}$ \\
\hline E4 & & $\begin{array}{l}\text { [4(\{[4-(N-(5-methyl-3-isoxazolyl) amino } \\
\text { sulfonyl) phenyl] amino }\} \text { methyl)-3-oxo-3,4- } \\
\text { dihydro-2H1,4-benzothiazin-2yl] acetic acid }\end{array}$ \\
\hline
\end{tabular}




\subsection{Spectral Data}

Spectral data of active compound E4 ([4(\{[4-(N-(5-methyl-3-isoxazolyl) amino sulfonyl) phenyl] amino methyl)-3-oxo-3,4-dihydro-2H1,4-benzothiazin-2yl] acetic acid ) was found to be IR (KBr, cm1 ): 3383.29(-NH str), 2989.79( $\mathrm{Ar}-\mathrm{CH}), 2920.35\left(-\mathrm{OH}\right.$ str), 1588.45 (C=O str), 1396.52( $\mathrm{SO}_{2}$ str), 1087.90(C-N str) 673.19(C-S str) Mass (m/e) 485 - molecular ion peak, $326\left[\mathrm{C}_{17} \mathrm{H}_{14} \mathrm{O}_{3} \mathrm{SN}_{2}\right]+$, $181\left(\left[\mathrm{C}_{9} \mathrm{H}_{9} \mathrm{O}_{2} \mathrm{~S}\right]+, 149\left[\mathrm{C}_{4} \mathrm{H}_{7} \mathrm{SO}_{3} \mathrm{~N}\right]+, \mathbf{U V}(\lambda \max ) 234 \mathrm{~nm}, 273 \mathrm{~nm}\right.$.

\subsection{Screening for antifungal activity}

Sabouraud dextrose agar media ${ }^{41}$ was prepared by using Mycological Peptone:10g, Dextrose: 40g, Agar: $15 \mathrm{~g}$, Final $\mathrm{pH}$ at $25^{\circ} \mathrm{C}: 5.4 \pm 0.2$, Water to make: $1000 \mathrm{ml}$. Sabouraud dextrose agar $65 \mathrm{~g}$ was suspended in $1000 \mathrm{ml}$ of distilled water and boiled to dissolve the mixture completely. The organism used, Candida albicans NCIM 3100 and Aspergillus niger NCIM 596 ${ }^{42}$, were procured from National Collection of Industrial Microorganisms National chemical Laboratory, Pune and stored in the Pharmaceutical Microbiology and Biotechnology Laboratory, St. James College of Pharmaceutical Sciences, St James College of Pharmaceutical Sciences, Chalakkudy, Kerala. Drug used: E1- E4, Standard used: Fluconazole $^{43}$, Vehicle used: Dimethyl sulphoxide (DMSO)

\subsubsection{Antifungal screening by Kirby-Bauer Method}

Sabouraud dextrose agar plates were prepared aseptically to get a thickness of 5-6mm and allowed to solidify. They were kept inverted to prevent the condensate from falling on the surface of the medium. The plates were dried at $25^{\circ} \mathrm{C}$, just before the incubation. The organism Candida albicans NCIM 3100 and Aspergillus niger NCIM 596 were inoculated in the respective plates prepared earlier by dipping sterile swab in the inoculums, removing the excess of inoculums by pressing and rotating the swab firmly against the sides of the culture tube above the level of the liquid. The swab was streaked all over the surface of the medium 3 times, rotating the plates through $60^{\circ} \mathrm{C}$ after each application. Finally the swab was pressed around the edges of the agar surface ${ }^{44}$.

The inoculation medium was left to dry at room temperature with the lid closed. Sterile discs containing the test, standard and blank were placed in the petridish aseptically. $10 \mu 1 /$ disc of the different drug concentration was used and kept in the refrigerator for 1hour to facilitate the uniform diffusion of the drug. Plates were prepared in triplicate and incubated at $25^{\circ} \mathrm{C}$ for $24-48$ hours. The diameter of the zone of the inhibition around the discs containing the drugs were measured and compared with those of standards. All the compounds were tested for antifungal activity against Candida albicans and Aspergillus niger. ${ }^{45}$ (Table No. 4).

Table No. 4: Antifungal Activity of Synthesized Compounds

\begin{tabular}{ccc}
\hline \multirow{2}{*}{ Compound Code } & \multicolumn{2}{c}{ Zone of Inhibition in mm } \\
\cline { 2 - 3 } & Candida albicans & Aspergillus niger \\
\hline E1 & 6 & 6 \\
E2 & 6 & 7 \\
E3 & 6 & 9 \\
E4 & 8 & 8 \\
DMSO (control) & - & - \\
Fluconazole & 18 & 17 \\
\hline
\end{tabular}

(-) indicates no zone of inhibition, Concentration used: $500 \mu \mathrm{g} /$ disc, Standard used: Fluconazole $10 \mu \mathrm{g} /$ disc 


\subsubsection{Determination of minimum inhibitory concentration: (MIC)}

The inoculums for the experiment were prepared fresh in Sabouraud dextrose broth from the preserved frozen slant culture. It was incubated for 24-48 hrs and used for the study after dilution to give 1:100 dilutions. The test organism used was diluted to 1:100 after overnight incubation and standard drop $(0.01 \mathrm{ml})$ was used for the MIC determination.

In vitro determination of the test sample was carried out by two fold serial dilution technique in Sabouraud dextrose broth with Candida albicans NCIM 3100 and Aspergillus nigerNCIM 596. The concentration range of the compounds used was $1000-1.95 \mu \mathrm{g} / \mathrm{ml}$. The test organism used was diluted to 1:100 after overnight incubation and standard drop $(0.01 \mathrm{ml})$ was used for the MIC determination.

Test tubes were sterilized, labeled as 1-11 and $1 \mathrm{ml}$ of Muller Hinton broth was added to each tube. They were autoclaved at a pressure of $15 \mathrm{psi}$ and $121^{\circ} \mathrm{C}$ temperature, for not less than 15 minutes. $1 \mathrm{ml}$ of diluted stock solution $(1000 \mu \mathrm{g} / \mathrm{ml})$ was added to the first tube and mixed. The serial transfer of $1 \mathrm{ml}$ lots through tube No.10 were carried out to obtain the quantities indicated. The pipette was discarded after each transfer and fresh pipette was used for transferring to the next tube and mixed.1 $\mathrm{ml}$ was discarded from the $10^{\text {th }}$ tube. The $11^{\text {th }}$ tube was used as control. With a standard micropipette, a drop of the diluted broth culture of the test organism was added to all the tubes, including the control. The contents of the test tube were mixed gently and the tubes were incubated at $37^{\circ} \mathrm{C}$ for $16-18$ hours and the results were observed. The above procedure was carried out in duplicate. The MIC was interpreted as the highest dilution of the test compound which shows clear fluid with no development of turbidity.(Table No : 5,Figure No:1)

Table no: 5 MIC values of synthesized compounds

\begin{tabular}{|c|c|c|c|c|c|c|c|c|c|c|c|}
\hline \multirow{2}{*}{ Comp code } & \multirow{2}{*}{ Organism } & \multicolumn{10}{|c|}{ Concentration in $\mu \mathrm{g} / \mathrm{ml}$} \\
\hline & & 1000 & 500 & 250 & 125 & 62.5 & 31.25 & 15.62 & 7.81 & 3.91 & 1.95 \\
\hline E1 & & $S$ & $\mathrm{~S}$ & $\mathrm{R}$ & $\mathrm{R}$ & $\mathrm{R}$ & $\mathrm{R}$ & $\mathrm{R}$ & $\mathrm{R}$ & $\mathrm{R}$ & $\mathrm{R}$ \\
\hline E2 & Candida & S & S & $\mathrm{R}$ & $\mathrm{R}$ & $\mathrm{R}$ & $\mathrm{R}$ & $\mathrm{R}$ & $\mathrm{R}$ & $\mathrm{R}$ & $\mathrm{R}$ \\
\hline E3 & albicans & $S$ & $S$ & $\mathrm{R}$ & $\mathrm{R}$ & $\mathrm{R}$ & $\mathrm{R}$ & $\mathrm{R}$ & $\mathrm{R}$ & $\mathrm{R}$ & $\mathrm{R}$ \\
\hline E4 & & S & S & S & $\mathrm{R}$ & $\mathrm{R}$ & $\mathrm{R}$ & $\mathrm{R}$ & $\mathrm{R}$ & $\mathrm{R}$ & $\mathrm{R}$ \\
\hline E1 & & S & S & $\mathrm{R}$ & $\mathrm{R}$ & $\mathrm{R}$ & $\mathrm{R}$ & $\mathrm{R}$ & $\mathrm{R}$ & $\mathrm{R}$ & $\mathrm{R}$ \\
\hline E2 & Aspergillus & $S$ & S & $\mathrm{R}$ & $\mathrm{R}$ & $\mathrm{R}$ & $\mathrm{R}$ & $\mathrm{R}$ & $\mathrm{R}$ & $\mathrm{R}$ & $\mathrm{R}$ \\
\hline E3 & niger & $S$ & $S$ & $\mathrm{R}$ & $\mathrm{R}$ & $\mathrm{R}$ & $\mathrm{R}$ & $\mathrm{R}$ & $\mathrm{R}$ & $\mathrm{R}$ & $\mathrm{R}$ \\
\hline E4 & & $S$ & $S$ & $\mathrm{R}$ & $\mathrm{R}$ & $\mathrm{R}$ & $\mathrm{R}$ & $\mathrm{R}$ & $\mathrm{R}$ & $\mathrm{R}$ & $\mathrm{R}$ \\
\hline $\mathrm{F}$ & & $S$ & $S$ & $S$ & $S$ & $S$ & $S$ & $S$ & $S$ & $\mathrm{~S}$ & $S$ \\
\hline
\end{tabular}

MIC of Synthesized Compounds against Candida albicans against fungi, $S$ - sensitive, $R$-resistant, $F$ - Fluconazole standard

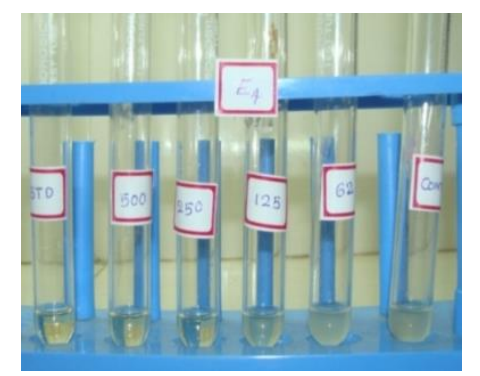

Figure No: 1. MIC of Synthesized Compounds against Candida albicans (Compound code: E4) 


\subsection{Molecular Docking Studies}

Molecular docking is routinely used for understanding drug information about drug receptor interactions, and is frequently used to predict the binding orientation of small molecule drug candidates to their protein targets in order to predict the affinity and activity of the small molecule The structures of the proteins were retrieved from Protein Data Bank. After obtaining the structure from Protein Data Bank ${ }^{46}$, the possible binding sites of the protein were searched using Computed Atlas of Surface Topography of Proteins (CASTp). The synthesized compounds (inhibitor) and target protein was geometrically optimized and docked using the docking engine Argus Lab. The synthesized compounds (inhibitor) and target protein was geometrically optimized and docked using the docking engine Argus Lab.

The different steps involved in the molecular docking studies. In Target identification and retrieval Crystallographic structure of the targets of interest were obtained from Protein Data Bank and saved in standard 3D co-ordinate format. In the next step water molecules present in the protein were removed and saved the protein without water ${ }^{47}$. All targets were possessing natural ligand and so active site residue identification was carried out taking advantages of the same. After obtaining the structure from Protein Data Bank, the possible binding sites of the protein were searched using Computed Atlas of Surface Topography of Proteins (CASTp). Hydrogen atoms missing in the PDB structure were added using Argus lab. Furthermore the atom list of the molecules were prepared, which represents the numbers of all the atom of the active site residues involved. The smiles formula of the drug molecules were obtained from chem. Sketch freeware version. . Then, using converter of the same server, PDB structure of the drug was converted into MDL MOL format which is an acceptable form for any standard docking software ${ }^{48}$. Finally using Argus lab, ligand molecules were prepared by the addition of hydrogen atom. Docking studies can be carried out using docking softwares like GOLD (genetic optimization and ligand docking), Argus lab, Autodock, GLIDE, Moligro virtual docker etc. here the software used is Argus lab. Entire process must be carried out with minimum speed and maximum accuracy ${ }^{49}$.

\subsubsection{Lipinski's rule of five}

Chemical data bases can contain thousands of molecules that could be a suitable ligand for the receptor. But no matter how good the fit is to the receptor, the candidate molecule is of no use if the absorption is poor or the drug is entered too slowly from the body. Compounds usually must fit within the defined limits that estimate absorption, distribution metabolism and excretion. An analysis of 2,245 drugs has led a set of rules called the Lipinski's rule of five ${ }^{50}$. Lipinski's rule of five is a thumb to evaluate drug likeness, if a chemical compound with a certain pharmacological or biological activity has properties that would make it a likely orally active drug in humans. The rule describes molecular properties important for a drug's pharmacokinetic in the human body including the ADME. However the rule does not predict if a compound is pharmacologically active or not.

The rule is important for drug development were a pharmacologically active lead structure is optimized step wise for increased activity and selectivity. Lipinski's rule states that, in general, an orally active drug has not more than one violation of the following criteria are Molecular weight should not be greater than 500 , Number of hydrogen donors ( $\mathrm{NH}, \mathrm{OH}$ ) should be fewer than 5, Number of hydrogen bond acceptors should be fewer than 10 and Calculated $\log \mathrm{P}$ values should be less than 5.This rule of five is designed as yes/no filter for the rejection of structures ${ }^{51}$. 
The drug likeness values are Partition coefficient $\log \mathrm{P}$ is -0.4 to 5.6 ranges, molar refractivity is from 40 to 130, Molecular weight should be in the range of 160 to 500, number of atoms should be in the range of 20 to 70.( includes H bond donors ( OHs and NHs) and H bond acceptors (Ns and Os)Polar surface area should not be greater than 140 A. Binding energy of all the synthesized compounds against the target protein 3QLS shown in Table No:6 and Figure No 2 and 3).

Table No: 6 Summary of binding energy of all the synthesized compounds against the target protein 3QLS (Antifungal Activity against Candida albicans)

\begin{tabular}{lclc}
\hline Compound code & Binding energy $(\mathrm{kcal} / \mathrm{mol})$ & No of conformations & No of hydrogen bonds \\
\hline & & & NIL \\
E1 & -11.5924 & 140 & NIL \\
E2 & -11.9342 & 140 & NIL \\
E3 & -12.0457 & 140 & $\mathbf{2}$ \\
E4 & $\mathbf{- 1 2 . 0 4 1 4}$ & $\mathbf{1 4 0}$ & 3 \\
FLUCONAZOLE (Std) & -8.9046 & 140 & \\
\hline
\end{tabular}
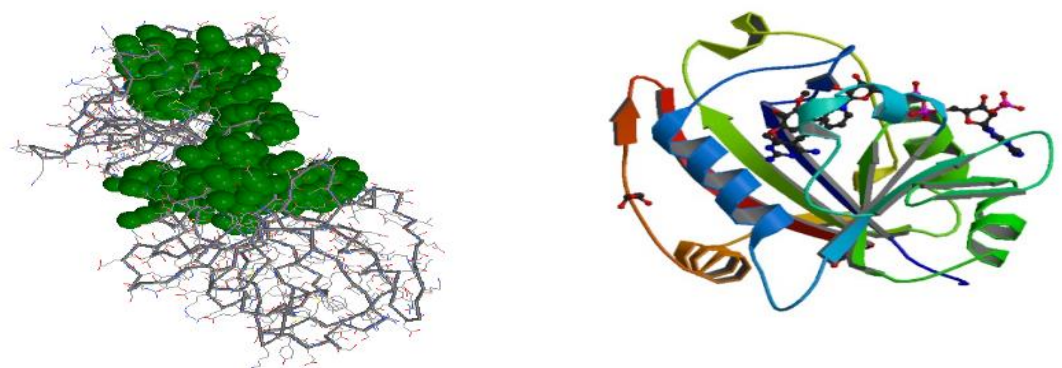

Figure No 2: Structure of $3 Q L S$ and Active sites of PDB ID: $3 Q L S$

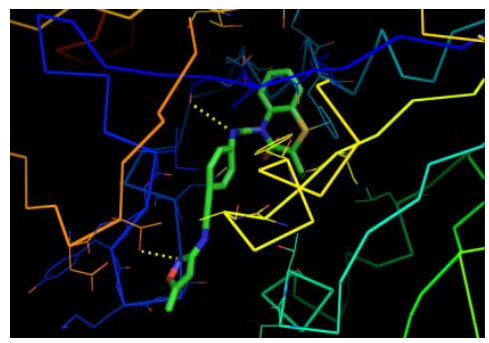

Figure No 3: Docking complex of PDB ID 3QLS with E4

\section{RESULTS AND DISCUSSION}

Four different 1, 4 thiazine derivatives were synthesized according to the scheme. The structures of the synthesized compounds were confirmed on the basis of physical characteristics such as M.P, TLC, solubility and \% yield. The synthesized thiazine derivatives (E1-E4) were carried out for antifungal activities. 
All the newly synthesized derivatives were screened for antifungal activity against Candida albicans NCIM 3100 and Aspergillus niger NCIM 596 by agar diffusion method (Kirby- Bauer method) using fluconazole $(10 \mu \mathrm{g} / \mathrm{disc})$ as the standard and dimethyl sulphoxide as the vehicle. $500 \mu \mathrm{g} / \mathrm{disc}$ concentration was used for all the test compounds. The results were interpreted as per Kirby- Bauer method. The newly synthesized compound E1, E2 and E3 were active and compounds against the test microorganism

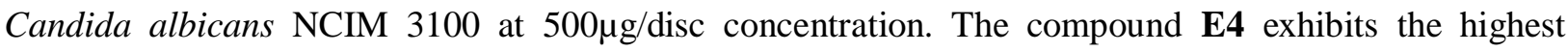
activity.

The newly synthesized compounds, E1, E2, E3 and E4 were active and compounds against the test microorganism Aspergillus niger NCIM 596 at 500 $\mathrm{g} / \mathrm{disc}$ concentration. All the newly synthesized compounds exhibited antifungal activity against all the microorganisms. The MIC of the compounds was determined against the two test microorganisms. The MIC of the compounds E4 against Candida albicans and Aspergillus niger was found to be $250 \mu \mathrm{g} / \mathrm{ml}$.

Molecular docking studies of the synthesized thiazine derivatives (E1-E4) were carried out for antifungal activities using Argus lab software.The compound E4 exhibits the highest activity.

\subsection{Lead molecule}

Among the synthesised compounds, compounds E4 [4(\{[4-(N-(5-methyl-3-isoxazolyl) amino sulfonyl) phenyl] amino\} methyl)-3-oxo-3,4-dihydro-2H1,4-benzothiazin-2yl] acetic acid shows highest antifungal activity due to the presence of 1,4- thiazine with sulfamethoxazole substitution. Binding energy against the target protein $3 \mathrm{QLS}$ was $-12.0414 \mathrm{Kcal} / \mathrm{mol}$.

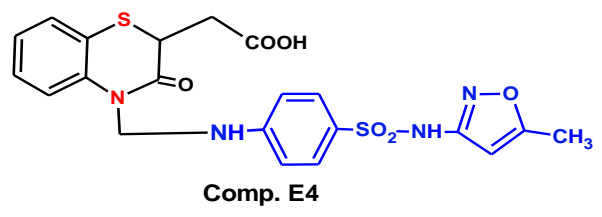

\section{SUMMARY AND CONCLUSION}

Fungal infections remain one of the biggest public health problems in the $21^{\text {st }}$ century. Although many active antifungal agents have been developed, the emergence of resistance to these agents is a pressing concern for human health. It is a leading cause for new challenges for the prevention, treatment and control of this deadly disease, the investigation for a new drug target is essential to continue the battle against drug resistance. The Mannich bases of 1, 4-thiazine derivatives are interesting groups of heterocyclic compounds exhibiting diverse pharmacological activities. The present work was made to find out more active new thiazine derivatives by antifungal studies. Then synthesised Mannich bases were also docked against Dihydrofolate reductase complexed with NADPH and 6- methyl-5- [3-methyl3-(3,4,5-trimethoxyphenyl)but-1-yn-1-yl]pyrimidine-2,4-diamine (UCP115A)using Argus Lab software.On this basis, we selected $3 \mathrm{QLS}$ as a biological target for docking study of synthesized compound. 
From the above results, it would be concluded that studies show that the Mannich bases of 1, 4-thiazine derivatives possess good anti fungal activity. The life threatening nature of fungal disease as one of the current thrust area of drug research and hence it is planned to take up experimental as well as the QSAR studies in future with suitable molecular modifications of the presently synthesized compounds with this scheme with potential lead compounds for better biological activities and lesser adverse reaction in future.

\section{Acknowledgement}

We are very thankful to St.James college of Pharmaceutical sciences for providing laboratory facilities, necessary instrumental facilities and kind support and Dr.K.R.Vinod, Principal, Sanjo college of Pharmaceutical studies for valuable suggestions and editorial works which have substantially contributed to improve the credibility of this article.

\section{References}

1. Bagher Eftekhari-Sis, Maryam Zirak and Ali Akbari. Arylglyoxals in the synthesis of heterocyclic compounds. Chemical Review 2013; 113 (5): 2958-3043.CrossRef PMid: 23347156

2. Yuhong Ju and Rajender S. Varma. Aqueous N-Heterocyclization of Primary Amines and Hydrazines with Dihalides: Microwave-Assisted Syntheses of N-Azacycloalkanes, Isoindole, Pyrazole, Pyrazolidine, and Phthalazine Derivatives. Journal of Organic. Chemistry. 2006; 71 (1):135-141. CrossRef

3. D. Zárate-Zárate, R. Aguilar, R. I. Hernández-Benitez, E. M. Labarrios, F. Delgado and J. Tamariz, Tetrahedron 2015;71: 6961-6978. CrossRef

4. Adel Nefzi, John M. Ostresh, and Richard A. Houghten. The Current Status of Heterocyclic Combinatorial Libraries. Chemical review.1997; 97 (2): 449-472. CrossRef PMid:11848878

5. P. D. Leeson and B. Springthorpe, The influence of drug-like concepts on decision-making in medicinal chemistry. Nature Review Drug Discovery, 2007; 6(11): 881-890. CrossRef

6. Copper-Catalyzed Aerobic $\mathrm{C}\left(\mathrm{sp}^{2}\right)-\mathrm{H}$ Functionalization for $\mathrm{C}-\mathrm{N}$ Bond Formation: Synthesis of Pyrazoles and Indazole .Journal Oragnic Chemistry 2013;78 (8): 3636-3646. CrossRef PMid:23547954

7. Annaleise R. Howard Jones and Christopher T. Walsh. Staurosporine and Rebeccamycin Aglycones Are Assembled by the Oxidative Action of StaP, StaC, and RebC on Chromopyrrolic Acid. Journal of American Chemical Society, 2006; 128 (37): 12289-12298. CrossRef PMid:16967980

8. Saied M. E. Khalil, Magdy Shebland Faizah S. Al-Gohani. Zinc (II) Thiosemicarbazone Complex As a Ligand Towards Some Transition Metal Ions: Synthesis, Spectroscopic and Antimicrobial Studies. Coord. Chem., 2003; 56: 1013-1024.

9. Denisa Leonte, László Csaba Bencze, Csaba Paizs, Florin Dan Irimie and Valentin Zaharia. Biocatalytic Synthesis of New Heterocyclic Mannich Bases and Derivatives Molecules 2015; 20(7):12300-12313.

10. Advanced Organic Chemistry: Reactions, Mechanisms, and Structure, John Wiley\& Sons, New York, NY, USA, 3rd edition, 1985

11. V. J. Belinelo, G. T. Reis, G. M. Stefani, D. L. Ferreira-Alves, and D. Pil'o-Veloso, "Synthesis of $6 \alpha, 7 \beta$ dihydroxyvouacapan- 17 $\beta$-oic acid derivatives. Part IV: Mannich base derivatives and its activities on the electrically stimulated guinea-pig ileum preparation," Journal of the Brazilian Chemical Society, 2002; 13(6): 830-837.

12. S. Joshi, N. Khosla, and P. Tiwari. "In vitro study of some medicinally important Mannich bases derived from antitubercular agent," Bioorganic \&Medicinal Chemistry, 2004; vol.12 (3):571- 576. CrossRef

13. L. Racane, V. T. Kulenovic, L. F. Jakic, D. W. Boykin, and G. K. Zamola, "Synthesis of bis-substituted amidinobenzothiazoles as potential anti-HIV agents. Heterocycles 2001; 55: 2085-2098. CrossRef

14. E. Kashiyama, I.Hutchinson, M.S. Chua et al., "Antitumor benzothiazoles. Synthesis, metabolic formation, and biological properties of the $\mathrm{C}$ - and N-oxidation products of antitumor 2- (4-aminophenyl)-benzothiazoles, Journal of Medicinal Chemistry, 1999; 42(20): 4172-4184. CrossRef

15. S. R. Bhusare, R. P. Pawar, and Y. B. Vibhute, "Synthesis and antibacterial activity of some new 2-(substituted phenyl sulfonamido)-6-substituted benzothiazoles. Indian Journal of Heterocyclic Chemistry, 2001; (11): 79-80. CrossRef

16. N. Raman, S. Esthar, and C.Thangaraja, "A new Mannich base and its transition metal (II) complexes-synthesis, structural characterization and electrochemical study. Journal of Chemical Sciences, 2004; 116 (4): 209-213. CrossRef

17. B. Kalluraya, R. M. Chimbalkar, and J. C. Hegde, "Anticonvulsant activity of nicotinyl/isonicotinyl substituted 1, 2,4triazol-5-thione Mannich bases," Indian Journal of Heterocyclic Chemistry, 2005 ; 15(1): 15-18. 
18. M. K"oksal, N. G"okhan, E. K"upeli, E. Yesilada, and H. Erdogan, "Analgesic and anti-inflammatory activities of some new Mannich bases of 5-nitro-2-benzoxazolinones. Archives of Pharmacal Research 2007; vol. 30(4):419-424. CrossRef

19. Y. Ivanova, G. Momekov, O. Petrov, M. Karaivanova, and V. Kalcheva. Cytotoxic Mannich bases of 6-(3-aryl-2propenoyl)- 2(3H)-benzoxazolones. European Journal of Medicinal Chemistry 2007; vol. 42(11-12\}:1382-1387. CrossRef

20. H. I. Gul, J. Vepsalainen, M. Gul, E. Erciyas, and O. Hanninen, "Cytotoxic activities of mono and bis Mannich bases derived from acetophenone against Renca and Jurkat cells. Pharmaceutica Acta Helvetiae 2000; vol. 74(4): $393-398$. CrossRef

21. M. Ashok, B. S. Holla, and B. Poojary, "Convenient one pot synthesis and antimicrobial evaluation of some new Mannich bases carrying 4-methylthiobenzyl moiety. European Journal of Medicinal Chemistry 2007; vol. 42(8):1095-1101. CrossRef

22. S. N. Pandeya, D. Sriram, G. Nath, and E. De Clercq, "Synthesis, antibacterial, antifungal and anti-HIV activities of norfloxacin Mannich bases. European Journal of Medicinal Chemistry 2000; vol. 35(2): 249-255. CrossRef

23. B. N. Singh, S. K. Shukla, and M. Singh, "Synthesis and biological activity of sulphadiazine Schiff's bases of isatin and their N-Mannich bases. Asian Journal of Chemistry 2007; (19): 5013-5018.

24. S. C. Vashishtha, G. A. Zello, K. H. Nienaber et al., "Cytotoxic and anticonvulsant aryloxyaryl Mannich bases and related compounds. European Journal of Medicinal Chemistry 2004; (39): 27-35.

25. E. Bennet-Jenkins and C. Bryant, "Novel sources of anthelmintics. International Journal for Parasitology, 1996; vol. 26(8): 937-947. CrossRef

26. D. Sriram, D. Banerjee, and P. Yogeeswari. Efavirenz. Mannich bases: synthesis, anti-HIV and antitubercular activities. Journal of Enzyme Inhibition and Medicinal Chemistry 2009 ;(24):1-5.

27. J. S. Mulla, A. Y. Khan, S. I. Panchamukhi, M. A. Khazi, M.B. Kalashetti, and I. M. Khazi, "Synthesis and antitubercular activity of Mannich bases of imidazo [2, 1-b] [1, 3, 4] thiadiazoles. Indian Journal of Novel Drug Delivery 2005; 3(4): 289295.

28. W. Malinka, P. 'Swia,tek, B. Filipek, J. Sapa, A. Jezierska, and A. Koll, "Synthesis, analgesic activity and computational study of new isothiazolopyridines of Mannich base type. Farmaco 2005; 60(11): 961-968. CrossRef

29. G. B. Barlin and C. Jiravinya. Potential antimalarials. X. Di- Mannich Bases of 4-( $7^{\prime}-$ Trifluoromethyl- $1^{\prime}, 5^{\prime}-$ naphthyridinylamino)phenol and $\mathrm{N}$-(4'-Diethylamino-1'-methylbutyl)-7-trifluoromethyl-1,5-naphthyridin-4-amine. Australian Journal of Chemistry. 1990; 43(7): 1175-1181. CrossRef

30. M. K. Scott, G. E. Martin, D. L. DiStefano et al. Pyrrole Mannich bases as potential antipsychotic agents. Journal of Medicinal Chemistry 19923; 5(3): 552-558.

31. M. L. Edwards, H.W. Ritter, D.M. Stemerick, and K. T. Stewart. Mannich bases of 4-phenyl-3-buten-2-one: a new class of antiherpes agent. Journal of Medicinal Chemistry 1983; 26 (3): 431-436. CrossRef

32. J. R. Dimmock and P. Kumar, "Anticancer and cytotoxic properties of Mannich bases. Current Medicinal Chemistry, 19974; (1):1-22.

33. J.-X. Ji,L.-Q.Qiu, C.WingYip, and A.S.C.Chan, "Aconvenient, one-step synthesis of optically active tertiary aminonaphthol and its applications in the highly enantio selective alkenylations of aldehydes. The Journal of Organic Chemistry 2003; 68(4):1589-1590. CrossRef

34. P.-J. J. Huang, D. Youssef, T. S. Cameron, and A. Jha. Microwave- assisted synthesis of novel 2-naphthol bis-Mannich Bases. Arkivoc, $2008 ;(16): 165-177$.

35. M. Arend, B. Westermann, and N. Risch, "Modern variants of the Mannich reaction. Angewandte Chemie-International Edition 1998; 37 (8): 1045-1070. CrossRef

36. B. S. Holla, M. K. Shivananda, M. S. Shenoy, and G. Antony, "Studies on arylfuran derivatives. Part VII. Synthesis and characterization of some Mannich bases carrying halophenylfuryl moieties as promising antibacterial agents. Farmaco 1998; vol. 53: 531-535.

37. M. K. Shivananda et al, Antifungal activity studies of some Mannich bases carrying nitrofuran moiety. Journal of Chemical and Pharmaceutical Research, 2011; 3(2):303-307.

38. Richardson MD, Warnock DW. Fungal infection: Diagnosis and Management, $3^{\text {rd }}$ Edition, 2003.

39. Paulsen JL, Bendel SD, Anderson AC. Crystal structures of Candida albicans dihydrofolate reductase bound to propargyllinked antifolates reveal the flexibility of active site loop residues critical for ligand potency and selectivity. Chemical Biology and Drug Design 2011 Oct; 78(4):505-12. CrossRef PMid:21726415, PMCid:PMC3171590

40. A.R Bhat and Pawar P.D, Synthesis and biological evaluation of some [1,4]-thiazin-2-one and [1,4]-oxazin-2-one derivatives. Indian drugs 2008; 45(12). 962-965.

41. Atlas RM, Perks LG, Brown AF. Laboratory Manual of Experimental Microbiology. Mosby Publishers. Louisville; 1995.

42. Mackienand McCartney. Practical Medical Microbiology. 14 ${ }^{\text {th }}$ ed. Churchchill Livingstone, New York; 1996.

43. Cappuccino JG, Sherman N. Microbiology- A Laboratory Manual. $3^{\text {rd }}$ ed. Benjamin Cummings Publishing Company, New York; 1992

44. Linnette EH, Balows A, Hauser W J. Manual of Clinical Microbiology. $4^{\text {th }}$ ed. Washington D. C. $1985 ; 1003$.

45. Lorian V. Antibiotic in Laboratory Medicine. $3^{\text {rd }}$ Edition. Williams and Wilking. USA; 1980.

46. Helen M Berman, John Westbrook, Zukang Feng. The protein Data Bank Nucleic Acid Research, 2000; 28 (1): $235-242$.

47. Ganewar P., Santhalingam K., George S., Meena C., Gururagavan M. Molecular Docking Studies of Novel 3- substituted phenyl- 2- (furan-2-yl)- 4H- chromen-4- ones as inhibitors of Interleukin 13 for Asthma; International Journal of Research in Pharmaceutical and Biomedical Sciences 2011 ; 2(3):1010-1014. 
48. Shiny G, Pallavi G, Meena C, Santhalingam K, Rajasekar D. Molecular modeling of 3,5,7- trihydroxy-2- (4- hydroxyl-3methoxy phenyl)-4h- chromen-4- one derivatives against II-6 for rheumatoid Arthritis; Asian J. Research Chem 2011;4(8): 1254-1257.

49. Harish R, Deshmukh R Veerasamy R. Novel Semicarbazones based 2, 5- substituted - 1, 3, 4- oxadiazoles; One more step towards establishing four binding site pharmacophoric model hypothesis for anticonvulsant activity. Bioorganic and Medicinal Chemistry Letters 2010; 20: 4168-4172. CrossRef

50. Severinsen R, Killburn JP, Ajaerpe FL, Versatile Strategies for the Solid Phase Synthesis of Small Heterocyclic Scaffolds: $(1,3,4)$ - thiadiazoles and $(1,3,4)$ - oxadiazoles. Tetrahedron 2005; 610: 5565-5575. CrossRef

51. Virupakshaiah DBM, Madiha Ahmed, Smita T. Patil, Chandrakanth Kelmani. Molecular Docking Studies of Mycobacterium tuberculosis RNA polymerase $\beta$ Subunit Receptor. World Academy of Science, Engineering and Technology 2013; 77: 431-436. 